\title{
MIKROALGA DIVISI BACILLARIOPHYTA YANG DITEMUKAN DI SUNGAI KASIE KECAMATAN LUBUKLINGGAU BARAT I KOTA LUBUKLINGGAU
}

\author{
Meika Aryani, Linna Fitriani, Harmoko*, Sepriyaningsih \\ Pendidikan Biologi STKIP PGRI Lubuklinggau \\ *E-mail: putroharmoko@gmail.com
}

\author{
Naskah diterima, dan disetujui (diisi oleh tim redaksi, TNR-11, bold, rata tengah)
}

\begin{abstract}
This research is a type of qualitative descriptive research. Data collection techniques by conducting observations, documentation and interviews. The types of microalgae found in the Kasie River Lubuklinggau Barat I Subdistrict, Lubuklinggau City. Bacillariophyta Division consists of one classes, 6 orders, 6 families, 9 genera and 15 spesies. Observed environmental factors: temperature: $27^{\circ} \mathrm{C}, \mathrm{pH}$ : 6,8 , Brightness: $0,70 \mathrm{~m}$ and dissolved oxygen amount of: $5,03 \mathrm{mg} / \mathrm{L}$. the type of microalgae division bacillariophyta were found in River Kasie namely: Tabellaria sp, Tabellaria flocculosa, Asterionella sp, Meridion sp, Meridon circulare, Synedra ulna, Synedra rumpens, Synedra sp 1, Synedra sp 2, Surirella linearis, Surirella elegans, Stenipterobia sp, Nitzschia intermedia, Navicula radiosa and Cymbella kappi.
\end{abstract}

Keyword: Bacillariophyta, Lubuklinggau, Microalgae, River Kasie.

\section{PENDAHULUAN}

Kota Lubuklinggau merupakan salah satu kota yang menjadi bagian wilayah Provinsi Sumatera Selatan. Kota Lubuklinggau terletak pada daerah tropis basah dengan curah hujan rata-rata 2000 s.d $2500 \mathrm{~mm}$ pertahun dimana setiap tahunnya jarang sekali ditemukan bulan-bulan kering. Luas wilayah Kota Lubuklinggau terdiri dari $66,5 \%$ dataran rendah yang subur dengan struktur $62,75 \%$ tanah liat dan keadaan alamnya terbagi atas hutan potensial, sawah, ladang, kebun karet dan kebun lainnya. Kota Lubuklinggau dilalui sungai besar yaitu Sungai Kelingi, Sungai Malus, Sungai Ketuan, Sungai Kati, Sungai Kasie dan Sungai lainnya yang berhulu di bagian barat dan mengalir ke arah timur (Effendi, 2008). Sungai Kasie adalah sungai yang terletak di Kecamatan Lubuklinggau Barat 1, Kota Lubuklinggau, dengan aliran sungai yang jernih dan sejuk. Air yang mengalir di sepanjang sungai tersebut dengan panorama alam yang indah sehingga menarik masyarakat untuk mengunjunginya. Sungai Kesie ini terletak di lereng bukit sulap dan juga sungai ini sering digunakan oleh penduduk sekitar untuk mandi dan mencuci. Sungai Kasie memiliki berbagai macam kekayaan sumber daya hayati di mana salah satu contohnya yaitu mikroalga.

Mikroalga sebagai tumbuhan mikroskopis bersel tunggal yang hidup di lingkungan perairan, tumbuh dan berkembang dengan memanfaatkan sinar matahari sebagai sumber energi dan nutrien anorganik seperti $\mathrm{CO}_{2}$, komponen nitrogen terlarut dan fosfat. Kemampuan mikroalga (mikroalga) untuk berfotosintesis, seperti tumbuhan darat lainnya, dapat dimanfaatkan seoptimal mungkin untuk menyerap $\mathrm{CO}_{2}$ (Sopiah et al, 2012). Selain itu Mikroalga juga dapat dijadikan sebagai indikator biologis dalam pencemaran air sungai (Widiana, 2012). Tujuan penelitian ini yaitu untuk mengetahui jenis-jenis mikroalga divisi Bacillariophyta yang ada di Sungai Kasie Kecamatan Lubuklinggau Barat I Kota Lubuklinggau.

\section{METODE}

berdasarkan kriteria ekosistem yang berbeda, dengan tiga pengulanagan waktu pengambilan dari bulan April-Mei 2019. 
Hal-hal ini dimaksudkan untuk melihat variasi jenis mikroalga yang ada di Sungai (Andriansyah et al, 2014). Sampel mikroalga kemudian diamati dan diidentifikasi di Laboratorium Biologi STKIP PGRI Lubuklinggau.

Alat penelitian yang digunakan dalam penelitian ini adalah plankton net ukuran 20 mesh, mikroskop listrik, $\mathrm{pH}$ meter, secchi disk, thermometer dan DO. Bahan yang digunakan dalam penelitian ini adalah sampel air dan etanol $85 \%$.

Prosedur dalam penelitian adalah sebagai berikut: (1) Penentuan stasiun pengambilan sampel mikroalga, (2) Pengukuran faktor fisik di masing-masing di Sungai Kasie yang meliputi: suhu, kecerahan, oksigen terlarut dan keasaman ( $\mathrm{pH}),(3)$ selanjutnya mengambil sampel air, dan disaring dengan plankton net, (4) Sampel mikroalga selanjutnya dipindahkan dan ditampung ke botol dengan cara di semprot denga spray, (5) Sampel kemudian diberi etanol 85\% 2-3 tetes, di tutup dan diberikan label, (6) Lakukan hal yang sama pada setiap stasiun, sebanyak 3 stasiun, dan (7) Setelah pengambilan sampel mikroalga selesai, sampel kemudian dianalisis dan diindentifikasi (Suwono, 2013).

Indentifikasi jenis mikroalga secara morfologi mengacu pada berbagai macam litelatur. Litelatur yang digunakan: Belcher \& Swale (1978), Vuuren, et.al (2006), Bellinger \& Sigee (2010), Wehr \& Sheath (2003) dan Botes (2001).

\section{HASIL DAN PEMBAHASAN}

\section{Faktor Abiotik di Sungai Kelingi Kota Lubuklinggau}

Pengukuran faktor abiotik di Sungai Kasie Kota Lubuklinggau dilakukan sebanyak tiga kali pengulangan saat dilakukan pengambilan sampel mikroalga. Faktor abiotic yang diukur meliputi: suhu, keasaman, kecerahan air dan oksigen terlarut. Hasil pengukuran factor abiotic dapat dilihat pada Tabel 1 berikut ini:

\section{Tabel 1. Faktor Abiotik Sungai Kasie Kota Lubuklinggau}

\begin{tabular}{ccc}
\hline No & Faktor Abiotik & $\begin{array}{c}\text { Nilai Rata- } \\
\text { rata }\end{array}$ \\
\hline 1 & Suhu & $27^{\circ} \mathrm{C}$ \\
2 & Keasaman & 6,8 \\
3 & Kecerahan & $0,70 \mathrm{~m}$ \\
4 & Oksigen terlarut & $5,03 \mathrm{mg} / \mathrm{L}$ \\
\hline
\end{tabular}

Nilai rata-rata faktor abiotik di Sungai Kasie Kota Lubuklinggau adalah Suhu dengan rata-rata $27^{\circ} \mathrm{C}$, keasaman dengan rata-rata 6,8 , kecerahan dengan rata-rata $0,70 \mathrm{~m}$ dan oksigen terlarut dengan rata-rata 5,03 $\mathrm{mg} / \mathrm{L}$.

2. Jenis Mikroalga Divisi Bacillariophyta di Sungai Kasie Kota Lubuklinggau

Penelitian mikroalga divisi bacillariophyta di Sungai Kasie Kota Lubuklinggau dilakukan pada 3 stasiun, masing-masing stasiun terdapat 3 titik dan pengambilan sampel dilakukan dengan 3 kali pengulangan (per minggu). Hasil identifikasi mikroalga divisi bacillariphyta dapat dilihat pada tabel 2 berikut ini.

Mikroalga divisi bacillariophyta yang ditemukan di Sungai Kasie Kota Lubuklinggau terdiri dari 6 Ordo, 6 Famili, 9 Genus dan 15 spesies. 


\section{Tabel 2. Mikroalga Divisi Bacillariophyta di Sungai Kasie, Kota Lubuklinggau}

\begin{tabular}{cccc}
\hline Ordo & Famili & Genus & Spesies \\
\hline Tabellariales & Tabellariaceae & Tabellaria & Tabellaria $\mathrm{sp}$ \\
& & Tabellaria flocculosa \\
& & Asterionella & Asterionella $\mathrm{sp}$ \\
& & Meridion & Meridion circulare \\
Fragilariales & Fragilariaceae & Synedra & Meridion $\mathrm{sp}$ \\
& & & Synedra ulna \\
& & & Synedra rumpens \\
& & & Synedra $\mathrm{sp}$ 1 \\
Surirellales & Surirellaceae & Surirella & Synedra $\mathrm{sp}$ 2 \\
& & & Surirella linearis \\
& & Stenopterobia & Surirella elegans \\
Bacillariales & Bacillariaceae & Nitzschia & Nitzschia intermedia \\
Naviculales & Navicullaceae & Naviculla & Naviculla radiosa \\
Cymbellales & Cymbellaceae & Cymbella & Cymbella kappi \\
\hline
\end{tabular}

\section{PEMBAHASAN}

Divisi Bacillariophyta terdiri dari diatom-diatom, biasa ditemukan di air tawar, air laut tanah yang lembab, memiliki kemampuan menempel pada substrat (Andriansyah et al, 2014), bersifat unisesuler, berkoloni atau membentuk filamen, dan setiap sel mengadung satu nukleus. Bacillariophyta sangat tergantung pada kualitas dan kuantitas senyawa kimia yang terlarut dalam air (Pratiwi, 2008; Widiana, 2012). Bacillariophyta sering dijumpai dalam jumlah besar dan banyaknya mikroalga tersebut diperairan disebabkan oleh kemampuannya beradaptasi dengan lingkungan, bersifat kosmopolit, tahan terhadap kondisi ekstrim serta mempunyai daya reproduksi yang tinggi. Bacillariophyta juga dapat digunakan sebagai bioindikator (Harmoko \& Krisnawati, 2018; Harmoko \& Sepriyaningsih, 2019). Bacillariophyta atau diatom umum ditemukan sebagai kelompok produsen primer dominan maupun subdominan kecuali pada sungai berlumpur (Zulkifli et al., 2009; Sundari, 2016; Winahyu et al., 2013).

Mikroalga Bacillariophyta yang ditemukan di Sungai Kasie Kota
Lubuklinggau yaitu: Tabellaria sp, Tabellaria flocculosa, Asterionella sp, Meridion sp, Meridon circulare, Synedra ulna, Synedra rumpens, Synedra sp 1, Synedra sp 2, Surirella linearis, Surirella elegans, Stenipterobia sp, Nitzschia intermedia, Navicula radiosa dan Cymbella kappi. Genus Tabellaria merupakan genus yang berbentuk zig zag atau filament lurus dan sering juga terlihat berbentuk sel tunggal. Sel-sel berbentuk korset lonjong ke bujur sangkar dengan proyeksi menuju pusat korset) (Bellinger \& Sigee, 2010). Genus Tabellaria di Sungai Kasie ditemukan sebanyak 2 spesies, yaitu; Tabellaria sp, Tabellaria flocculosa.

Genus Asterionella merupakan genus dengan sel-sel tipis panjang mengembung di salah satu atau kedua ujungnya, sering membentuk koloni bintang (Billinger \& Sigee, 2010). Genus Asterionella di Sungai Kasie ditemukan sebanyak 1 spesies, yaitu; Asterionella sp. Genus Meridion dari koloni lingkaran atau radial, dalam tampilan korset katup berbentuk biji. Ada beberapa kloroplas kecil berbintik di sekitar sel (Bellinger \& Sigee, 2010). Genus Meridion di Sungai Kasie ditemukan sebanyak 2 
spesies, yaitu; Meridon circulare dan Meridon sp.

Genus Synedra sering mendominasi perifiton dan mungkin memiliki penampilan yang pendek, tebal dan berwarna coklat. Synedra seperti pensil tipis seperti sel, soliter atau kadang-kadang berkoloni berbentuk kipas (Bellinger \& Sigee, 2010). Genus Synedra termasuk golongan diatom yang berbentuk panjang. Bergerak dengan bebas sebagai planktonik dan melekat pada subtrat dengan lendir. Panjang sel mencapai 500 $\mu \mathrm{m}$ (Bellinger \& Sigee, 2010). Genus Synedra di Sungai Kasie ditemukan sebanyak 4 spesies, yaitu; Synedra ulna, Synedra rumpens, Synedra sp 1 dan Synedra sp 2.

Genus Surirella memiliki bentuk besar, elips atau oval, tampilan korset berbentuk persegi panjang, panjang sampai dengan 15 hingga $200 \mu \mathrm{m}$, hidup di kolam, danau dan sungai (Blecher \& Swale, 1978). Sisi lebih kecil, ujung kerucut. Ukuran khas panjang $20 \mu \mathrm{m}$ dan lebar $10 \mu \mathrm{m}$ (Bellinger \& Sigee, 2010). Genus Surirella di Sungai Kasie ditemukan sebanyak 2 spesies, yaitu; Surirella linearis dan Surirella elegans.

Genus Stenopterobia memiliki bentuk panjang dan terdapat kloroplas di pusatnya, lurus dan tidak bercabang-cabang. Spesies ini mempunyai panjang hingga $250 \mu \mathrm{m}$. Stenopterobia biasanya terdapat di danau dan sungai (Biggs \& Cathy, 2000). Genus Stenipterobia di Sungai Kasie ditemukan sebanyak 1 spesies, yaitu; Stenipterobia sp. Genus Nitzschia memiliki banyak spesies, panjangnya $5-100 \mu \mathrm{m}$, paling muda dibedakan dalam keadaan hidup dari Navicula dan sekutunya oleh dua kloroplas diujung sel, bukan disisi. Ada juga spesies sigmoid besar, panjangnya sampai $600 \mu \mathrm{m}$, tapi tidak seperti gyrosigma, ia memiliki sisi parallci dan ujungnya tumpul (Belcher \& Swale, 1978). Genus Nitzschia di Sungai Kasie ditemukan sebanyak 1 spesies, yaitu; Nitzschia intermedia. Genus Navicula berukruan sekitar $70 \mu \mathrm{m}$ dengan striae yang terlihat memancar dari daerah pusat. Spesies ini. Hidup di sungai, danau dan kolam. Striae biasanya memancar dari pusat (Biggs \& Cathy, 2000). Genus Navicula di Sungai Kasie ditemukan sebanyak 1 spesies, yaitu; Navicula radiosa.

Divisi Bacillariophyta yang ditemukan di Sungai Kasie Kota Lubuklinggau berjumlah 14 spesies, jumlah ini termasuk "sedang" jika dibandingkan dengan yang ditemukan di tempat lain di Kota Lubuklinggau. Air Terjun Watervang 3 spesies (Harmoko et al, 2017), Sungai Mesat 4 spesies (Harmoko et al, 2018), Air Terjun Temam 8 spesies (Harmoko et al, 2018) dan terbanyak ditemukan di Sungai Kati yaitu sebanyak 19 spesies (Harmoko \& Sepriyaningsih, 2017) dan terbanyak ditemukan di Sungai Kelingi sebanyak 53 Spesies (Harmoko \& Sepriyaningsih, 2019). Perbedaan ini disebabkan dari karakteristik sungai yang berbeda-beda dan juga disebabkan oleh faktor abiotik.

Faktor abiotik yang diukur yaitu suhu air Sungai Kasie. Hasil suhu pada penelitian yaitu rata-rata $27{ }^{\circ} \mathrm{C}$. Suhu optimal untuk mikroalga antara $24-30{ }^{\circ} \mathrm{C}$ (Kawaroe et al, 2010). Jadi, nilai suhu air Sungai Kasie dalam keadaan normal. Keasaman air Sungai Kasie yaitu 6,8. Menurut Maresi et al, (2015) Kisaran $\mathrm{pH}$ yang sesuai untuk kehidupan organisme perairan adalah 6,5-9. Jadi nilai keasaman air Sungai Kasie dalam keadaan normal. Hasil kecerahan pada penelitian rata-rata $0.70 \mathrm{~m}$. Menurut Maresi et al, (2015) perairan yang memiliki kecerahan 0,60 m-0,90 m dianggap cukup baik untuk menunjang kehidupan ikan dan organisme perairan dan kecerahan $<0,30 \mathrm{~m}$ dapat menimbulkan masalah bagi ketersediaan oksigen terlarut di perairan. Hasil DO pada penelitian dengan rata-rata $5,03 \mathrm{mg} / \mathrm{L}$. Kandungan DO di perairan yang dapat ditolerir oleh organisme akuatik terutama mikroalga adalah tidak kurang dari $5 \mathrm{mg} / \mathrm{L}$ (Maresi et al, 2015). Menurut PP No. 82 Tahun 2001, batas minimal kandungan DO untuk kategori kelas III (perikanan) yaitu $4 \mathrm{mg} / \mathrm{L}$. 


\section{SIMPULAN}

Berdasarkan hasil penelitian dan pembahasan, dapat disimpulkan bahwa: jenis mikroalga divisi Bacillariophyta yang ditemukan di Sungai Kasie yaitu: Tabellaria sp, Tabellaria flocculosa, Asterionella sp, Meridion sp, Meridon circulare, Synedra ulna, Synedra rumpens, Synedra sp 1, Synedra sp 2, Surirella linearis, Surirella elegans, Stenipterobia sp, Nitzschia intermedia, Navicula radiosa dan Cymbella kappi.

DAFTAR PUSTAKA

Andriansyah., Setyawati, T.R \& Lovadi, I. (2014). Kualitas Perairan Kanai Sungai Jawi dan Sungai Raya Dalam Kota Pontianak Ditinjau Dari Struktur Komunitas Mikroalga Perifitik. Jurnal Protobiont 3: 61-70.

Belcher. H \& Swale.E. (1978). A Beginner's Guide To Freshwater Algae. London: Institute of Terrestrial Ecology.

Bellinger, E. G., \& Sigee, D. C. (2010). Freshwater Algae. UK: Jhon Wily \& Sons, Ltd.

Biggs, B.J.F \& Cathy, K. (2000). Stream Periphyton Monitoring Manual. New Zealand: Niwa.

Botes, L. (2001). Phytoplankton Identification Catalogue. South Africa: Glaballast Monograph.

Effendi, R. (2008). Profil, Potensi \& Peluang Investasi Kota Lubuklinggau. Lubuklinggau: Kantor Penanaman Modal Kota Lubuklinggau Provinsi Sumatera Selatan.

Harmoko \& Sepriyaningsih. (2017). Keanekaragaman Mikroalga di Sungai Kati Kota Lubuklinggau. Scripta Biologica, 4: 201-205.

Harmoko, Lokaria, E., \& Misra, S. (2017). Eksplorasi Mikroalga di Air Terjun Watervang Kota Lubuklinggau. Bioedukasi, 8, 75-82.

Harmoko., Lokaria, E \& Sintya, A.D. (2018). Eksplorasi Mikroalga di Air Terjun Temam Kota Lubuklinggau,
Provinsi Sumatera Selatan. Jurnal Bioeksperimen 4: 75-80.

Harmoko., Triyanti, M \& Aziz, L. (2018). Eksplorasi Mikroalga Di Sungai Mesat Kota Lubuklinggau. Biodidaktika: Jurnal Biologi dan Pembelajarannya, 13: 19-23.

Harmoko \& Krisnawati, Y. (2018). Mikroalga Divisi Bacillariophyta yang Ditemukan di Danau Aur Kabupaten Musi Rawas. Jurnal Biologi Universitas Andalas, 6: 30-35.

Harmoko \& Sepriyaningsih. (2019). Bioindikator Sungai dengan Mikroalga (Studi Kasus di Sungai Kelingi Kota Lubuklinggau). Yogyakarta: Deepublish.

Kawaroe, M. Prartono, T. Sunuddin, A. Sari, W.D. \& Augustine, D. (2010). Mikroalga Potensi dan Pemanfaatannya Untuk Produksi Bio Bahan Bakar. Bogor: IPB Press.

Maresi, S.R.P., Priyanti., \& Yunita, E. (2015). Mikroalga Sebagai Bioindikator Saprobitas Perairan Di Situ Bulakan Kota Tangerang. Al Kauniyah; Jurnal Biologi. 8 : 113122.

Pratiwi, T.S. (2008). Mikrobiologi Farmasi. Jakarta: Erlangga.

Sundari, P.P.K. (2016). Identifikasi Fitoplankton di Perairan Sungai Pepe sebagai Salah Satu Anak Sungai Bengawan Solo di Jawa Tengah. Prosiding Seminar Nasional Pendidikan Biologi dan Saintek, UMS Solo 21 Mei 2016.

Sopiah, N. Mulyanto, A., \& Sehabudin, S. (2012). Pengaruh Kelimpahan Sel Mikroalga Air Tawar (Chlorella sp) Terhadap Penambatan Karbondioksida. Jurnal Teknik Lingkungan. 14: 1-6.

Suwono, H. (2013). Petunujuk Praktikum Limnologi. Malang: FMIPA Universitas Negeri Malang.

Vuuren, S.J.V., Jonathan.T, Carin. V.G., \& Annelise.G. (2006). Easy Identification of The Most 
Freshwater Algae. South African: North-West University noorowesuniversitiet.

Wehr, J.D., \& R.G.Sheath. (2003). Freshwater Algae Of Noert America. America: Academic Press.

Winahyu, A. D., Yulistia, A., Elly, L.R., Jani, M., \& Andi, S. (2013). Studi Pendahuluan Mengenai Keanekaragaman Mikroalga di Pusat Konservasi Gajah, Taman Nasional Way Kambas. In Semirata FMIPA Universitas Lampung.

Widiana, R. (2012). Komposisi Mikroalga Yang Terdapat Di Perairan Batang Palangki Kabupaten Sijunjung. Jurnal Pelangi, 5: 22-30.

Zulkifli H, Husnah, Ridho MR, Juanda S. (2009). Status Kualitas Sungai Musi Bagian Hilir Ditinjau Dari Komunitas Fitoplankton Journal of Biological Researches. 15: 5-9. 